\title{
THE NEXT GENERATION OF SMART CITIZENS: EXPERIENCES AND INSPIRATION FROM THE +CITYXCHANGE PROJECT
}

DOI: 10.18485/arh_pt.2020.7.ch1

\author{
Alenka Temeljotov-Salaj \\ Department of Civil and Environmental Engineering, Norwegian \\ University of Science and Technology, Høgskoleringen 7A, 7491 \\ Trondheim, Norway, alenka.temeljotov-salaj@ntnu.no
}

\section{_ Bradley Loewen \\ Department of Civil and Environmental Engineering, Norwegian University of Science and Technology, Høgskoleringen 7A, 7491 Trondheim, Norway, bradley.loewen@ntnu.no}

\section{ABSTRACT}

Environmental sustainability has become a core objective in policy fields related to the built environment, from the international to local level. The transition to a sustainable built environment depends on increasing the energy performance of buildings, but due to the maturity of the building stock in Europe affecting energy efficiency and the current incentives for investing in sustainable energy solutions, the performance of buildings cannot be improved without widespread citizen engagement. Technical solutions for upgrading smart buildings and connecting them are being developed that create new opportunities for achieving a net-zero or even positive energy balance on the neighbourhood, district and city level. Nevertheless, attention must also be paid to the social aspect using citizen engagement to ensure that such solutions are taken up and replicated. From a social perspective, new skills and values are needed amongst citizens to improve individual and collective behaviours. Co-creation is an approach for shaping the urban environment that includes a wide range of stakeholders and is believed to lead to improved outcomes, especially with regard to integrating users' needs and generating a sense of shared responsibility and ownership over the built environment.

The Horizon 2020 project +CityxChange uses co-creation for the development of positive energy districts (PEDs), which have the potential to bring carbon neutral cities to reality. The paper explores several aspects of citizen engagement developed in the project: an urban innovation lab approach, a citizen participation playbook, learning framework for the next generation of smart citizens, and framework for creating positive energy champions.

KEYWORDS _ built environment, energy, co-creation, citizen engagement, smart cities

\section{INTRODUCTION}

In recent years, European policies have converged on the global aim of low-carbon energy transition and approach of citizen participation. Following the United Nations' Agenda 2030 and Sustainable Development Goals (SDGs) (UN, 2015), ambitious actions have been pursued for achieving carbon neutrality in the building sector including energy and resource efficiency, upgrading and retrofitting industry and infrastructure and fostering inclusive and participative processes for sustainable cities and communities. Most recently, the European Green Deal aims to make the EU carbon neutral by 
2050 (EC, 2019a).

Since the United Nations' Agenda 21 was introduced in 1992, the approach for achieving global goals such as the SDGs and Europe's own climate targets has favoured localization (UNCED, 1992) - that is, by translating international targets to local needs and actions for implementation on the lowest levels. In Europe, local actions are necessary to develop and implement policies from the bottom up in order to hold political legitimacy and gain community support. For the European Green Deal, citizen participation is deemed necessary to make the energy transition just and inclusive (EC, 2019a). This is in accordance with SDG 11 - Sustainable cities and communities, which aims to "make cities and human settlements inclusive, safe, resilient and sustainable" (UN, 2015). Co-creation has thereby been pursued as a core element of urban development actions and EU projects, in particular.

Steps have been taken at European and national levels to translate energy targets to the building sector. Here, co-creation becomes part of planning and design in cities, while co-management and co-evaluation becomes part of urban facility management (urban FM) for the long-term sustainable management and user orientation of the built environment (Temeljotov Salaj et al., 2020, Lindqvist et al., 2020). Citizen participation has applications in all stages of the building lifecycle, looking beyond the traditional concerns of design and construction to long-term management, and can be an important aspect of energy education and investment in the energy transition. This is especially important for meeting citizens in the environments of their daily lives.

Support for the energy transition in the built environment can be found in the area of research and innovation for smart cities. An aim of the European Horizon 2020 research and innovation programme has been to transform the building stock to carbon neutrality and even create net positive producers of clean and renewable energy (EC, 2019b). A main challenge for the carbon-neutral built environment lies in the ability to scale and replicate solutions (Ahlers et al., 2019). Here, the human element needs serious attention to ensure the uptake of innovations. Urban environments are characterized by complex configurations of stakeholders with different competing and complementary interests. By involving citizens in the design, delivery and management of projects through innovative public-private-people partnerships (PPPPs), the urban environments developed to meet the environmental challenges and energy targets of the future can also meet the wider values of society. Citizen participation in smart cities development therefore has potential to improve the processes and outcomes of projects for meeting citizens' needs.

With the above in mind, this paper discusses co-creation in the built environment to create a new generation of smart citizens that will drive the sustainable transition of urban areas, drawing on early experiences and inspiration from the case of the Horizon 2020 project, +CityxChange1F with interventions in Trondheim, Norway, and Limerick, Ireland.

\section{POLICIES AND TARGETS FOR SUSTAINABLE BUILT ENVIRONMENT}

The main policies shaping the future sustainable built environment in Europe are being translated from international to national and eventually local actions. On the European level, the Strategic Energy Technology (SET) Plan (EC, 2018a), the Energy Efficiency Directive (EC, 2018b) and the Energy Performance in Buildings Directive (EPBD) (EC, 2018c) establish frameworks, guidelines and strategies for national energy performance levels. $2 \mathrm{~F}$ Buildings account for $40 \%$ of energy consumption in Europe (EC, 2018b), and the EU aims to make Europe carbon neutral by 2050 (EC, 2019a). A review of the building stock showed that $97.5 \%$ of buildings in Europe fall below energy class A (BPIE, 2017), which indicates that the biggest potential for improving energy efficiency lies in upgrading the existing stock of buildings. New buildings, on the other hand, should achieve net zero energy performance from 2020 onwards (EC, 2016) - a challenge that is yet to be met.

Technological guidelines and strategies for improving building performance address smart buildings, deep renovations and requirements for new buildings to be energy neutral, but, while these frameworks come into place, attention must increasingly be paid to ensuring their uptake amongst 
industry and citizens in general, lest their potentials be underutilized. According to the European Commission (2018d), "Moving towards a net-zero greenhouse gas economy can only be successful with citizens that embrace change, get engaged and experience it as beneficial for their lives and that of their children," and cities are deemed to become the "laboratories for transformative and sustainable solutions" (p. 22).

National implementations shall be suited to the contexts of climate conditions, building systems, governance frameworks, and so on. In Norway, the Norwegian Building Authority is responsible for implementing the EPBD, which has been a lengthy process due to delays in transposing the directive to Norway by the Ministry of Petroleum and Energy and in establishing a certification scheme by the Norwegian Energy Directorate (Haldorsen, 2016). The EPBD has yet to be fully implemented, but in spite of this, energy efficient solutions have long been envisioned to become the preferred choice for Norwegian consumers in the future (Ministry of Petroleum and Energy, 2012). As a signatory of the Paris Agreement, Norway has committed to a $40 \%$ reduction of greenhouse gas emissions compared to the 1990 level by 2030 (Ministry of Climate and Environment, 2017). Whereby housing represents $67 \%$ of the building stock in the country, the importance of addressing sustainability in this sector is reinforced (Temeljotov Salaj et al., 2020). Furthermore, the range of stakeholders to involve in the transition of this sector is wide and notably includes individual residents, which can present a challenge to coordination and management.

Co-creation can be considered in terms of user integration into innovation processes, which draws a link between citizen engagement and relationship management (Arnold, 2017). This is particularly relevant in the sustainable built environment, where facility managers maintain the relationships between building owners, investors and users and are tasked with ensuring the long-term performance of buildings in the life-cycle management system. The role of co-creation from the facility management perspective is therefore not only about general societal wellbeing in terms of broad sustainability goals, but it is also about corporate sustainability and supporting the local community. Moreover, it can be used to engage citizens with complex technical processes. While there is no generally accepted framework for co-creation, innovation workshops, virtual communities, idea competitions and stakeholder dialogues are counted amongst the tools available (Arnold, 2017). Playfulness and novelty are emphasized to gain citizens' engagement in such events as workshops and competitions.

\section{POSITIVE ENERGY DISTRICTS}

On the ground, the energy directives and strategies for achieving them must be transposed to and implemented in complex urban environments. Each building has its own possibilities improving performance and its unique set of stakeholders. Pooling buildings' opportunities and challenges can create synergies and reduce risks. The ultimate ambition of carbon neutral cities therefore calls for cooperation amongst buildings and stakeholders. This is demonstrated through the concept of Positive Energy Blocks and Districts (PEBs/PEDs), defined as "several buildings ... that actively manage their energy consumption and the energy flow between them and the wider energy system" resulting in a positive energy balance (EC, 2020, p. 171). PEDs shall be "well embedded in the spatial, economic, technical, environmental and social context of the project site" (p. 171). The configurations of PEDs can differ, from being physically proximate to virtually connected buildings. Common features include the pooling of energy production and consumption, including aspects of smart cities and buildings, deepening the so-called 'prosumer' role by which energy consumers also become producers, demand-side energy management, energy trading, etc. PEDs have the advantage of addressing multiple building performance improvement strategies promoted on the European level, such as deep refurbishment and smart building upgrades in existing buildings and new building zero energy requirements.

In addition to the technical benefits of PEDs, co-creation is seen as a promising strategy for stakeholder and citizen engagement in order to increase the prospects for widespread PED upscaling and 
replication (Ahlers et al., 2019), towards meeting Europe's target of 100 PEDs by 2025 (JPI Urban Europe, 2018).

\section{CASE PROJECT: +CITYXCHANGE}

The EU Horizon 2020 'Smart Cities and Communities' project, Positive City ExChange (+CityxChange), adopts a citizen-centred approach for the co-creation of PEDs in order to accelerate the clean energy transition (+CityxChange, 2019a). The project is led by the Norwegian University of Science and Technology (NTNU) and draws together 32 partners from 10 countries - including municipalities, industry, SMEs, non-profit organisations and universities - for 11 demonstration projects in 7 cities (Figure 1).

+ CityxChange envisions a transformation of the energy market through citizen and stakeholder participation in the planning, design, implementation and upscaling of PEDs (Figure 2). This involves both technical systems - towards smart grids, demand-side optimization, energy storage and trading markets, etc. - and community-based social innovations. The project was developed with stakeholders (including direct beneficiaries) in the early stages, which was widened towards citizen engagement (associated partners and other non-beneficiaries, citizens, etc.) in implementation. Through citizen engagement and co-creation, the project observes the interactions between stakeholders and citizens to improve wider PED deployment and derive suitable governance models to support the energy transition (Gohari et al., 2020).
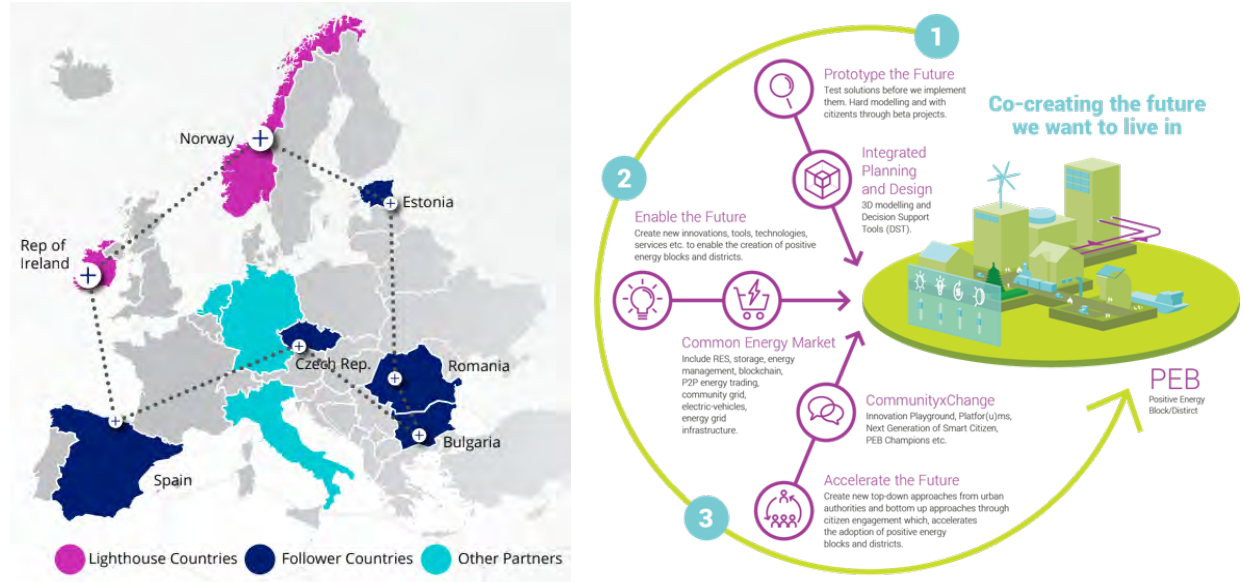

_ Figure 1 (left): +CityxChange project cities and partners (+CityxChange, 2019b) and Figure 2 (right): +CityxChange vision circle (CityxChange, 2019b)

Several frameworks for citizen participation developed within the project are based on partner experiences and best practices in other European projects. +CityxChange follows a developed Bold City Vision (BCV) framework (Figure 3) for strategic alignment and local anchoring and support, which further integrates with the goal of 100 PEDs in Europe by 2025 (JPI Urban Europe, 2018). The BCV elaborates a process beginning with engagement, followed by design, activation, acceleration and support stages across multiple dimensions of PED development (Tanum et al., 2019). For the citizen engagement aspect, these stages are acknowledgement, deliberation, localisation, connection and amplification. As a guiding principle, the city is used as a living lab. The project has collected tools and best practices to create frameworks for: Citizen Participation (playbook and platform); learning targeting the next generation of smart citizens; positive energy champions; innovation labs, and; innovation playgrounds. These frameworks are tackled from the perspective of supporting replica- 
ble activities, as physical and operational infrastructure towards the energy transition in cities. We hereby focus on four of these items in the following sections: citizen participation playbook, learning targeting the next generation of smart citizens, positive energy champions and innovation labs.

\begin{tabular}{|c|c|c|c|c|c|}
\hline & Engage & Design & Activate & Accelerate & Support \\
\hline క్ర్తి standardisation & Evaluation & Visualisation & Simulation & Funding & Sharing \\
\hline J్ policy & Review & Revision & Planning & Budgeting & Anialysis \\
\hline $\begin{array}{l}\text { Innovation } \\
\text { partnerships }\end{array}$ & Appointment & Linking & Collaborating & Prioritising & $\begin{array}{l}\text { Portfolio } \\
\text { management }\end{array}$ \\
\hline $\begin{array}{l}\text { Organisational } \\
\text { development }\end{array}$ & Idenification & Leadership & intrapreneurship & $\begin{array}{c}\text { Self } \\
\text { organisation }\end{array}$ & Twinning \\
\hline \&. & Acknowledgement & Deliberation & Localisation & Connection & Amplification \\
\hline $\begin{array}{l}\text { Project } \\
\text { \&ad development }\end{array}$ & Pitching & Prototyping & Delivering & Capitalising & Storytelling \\
\hline
\end{tabular}

_ Figure 3. Bold City Vision framework for 2050 (Tanum et al., 2019)

\section{Citizen Participation Playbook}

The citizen participation playbook is a roadmap of participatory processes to co-design PEDs (Burón and Sánchez, 2020). These processes include the co-design of urban interventions, collaborative legislation, participatory budgeting and facilitating citizens' proposals. Six best practices for effective citizen participation are listed in Table 1.

The playbook assembles physical and online tools that serve as a reference guide for local authorities. Firstly, the physical: narrative tools, co-design workshops, focus working groups, public engagement events, go and find citizens, mapping sessions and gamification. Secondly, the digital: collaborative text, online debate, online mapping, online voting, accountability, online proposals and participatory budgeting. In the implementation phase of the project, the playbook will be applied in the pilot cities. For Trondheim, the challenge is to overcome departmental silos for integrating participatory processes. The digital platform Decidim3F is being tested to implement the online tools.

_ Table 1. Best Practices in Citizen Engagement suggested for use by +CityxChange (Burón and Sánchez, 2020)

\section{Best Practices in Citizen Engagement}

1. Define the community

2. Clear purpose and front loading

\section{Benefits}

Effective and inclusive community engagement

Gain of credibility in the participatory process; Higher participation rates 


\begin{tabular}{l|l}
\hline $\begin{array}{l}\text { 3. Continuous engagement: capacity } \\
\text { building and feedback }\end{array}$ & Continuous communication; community ownership \\
\hline 4. Open process, open source, open data & Gain credibility, greater engagement, well-informed participation \\
\hline 5. Co-design, co-create and co-produce & Continuous citizen involvement; Ensures project implementation \\
\hline 6. Privacy by design & Increase citizen privacy and trust in the process
\end{tabular}

\section{Learning Framework targeting the Next Generation of Smart Citizens}

The framework is presented as a learning and education portfolio of information on learning activities and templates for the replication of learning activities (Avram, in draft), based on the experiences of project partners engaged in education. These include multi-generational activities and activities for specific age groups. In Trondheim, these activities have been focused on new courses and summer schools at NTNU for bachelor and master students, experts in teams courses, and the UngEnergi project $4 \mathrm{~F}$ that introduces various topics under theme of renewable energy to secondary students. The municipality has led events at citizen observatories including scavenger hunts, workshops and demonstrations of energy generation and storage solutions.

\section{Framework supporting Positive Energy Champions}

The framework's aim is to raise awareness of positive energy concepts and build citizen capacity to take action on the implementation and replication of PEDs (Fitzgerald and Mee, in draft). It will develop campaign formats and guidelines and toolkits for implementing the campaigns. A Positive Energy Champion is defined as an individual who fosters positive energy communities by incorporating related concepts into daily routines and encouraging fellow citizens.

\section{Innovation Labs}

The framework outlines the creation of innovation labs as centres for digital innovation in cities (Fitzgerald et al., in draft). The labs are set up as collaborative structures under the guiding principles of Open Innovation 2.0 ecosystem for entrepreneurs and start-ups (Curley and Salmelin, 2018). Relevant stakeholders for involvement are targeted according to the science, policy, industry and society facets of the Quadruple Helix Model. Innovation labs provide a forum for the earlier frameworks to be put into action and integrated with city governance systems and participatory processes to enable a co-creation culture in the community.

\section{CO-CREATION ACTIVITIES OF NTNU IN +CITYXCHANGE LIGHTHOUSE CITY OF TRONDHEIM, NORWAY}

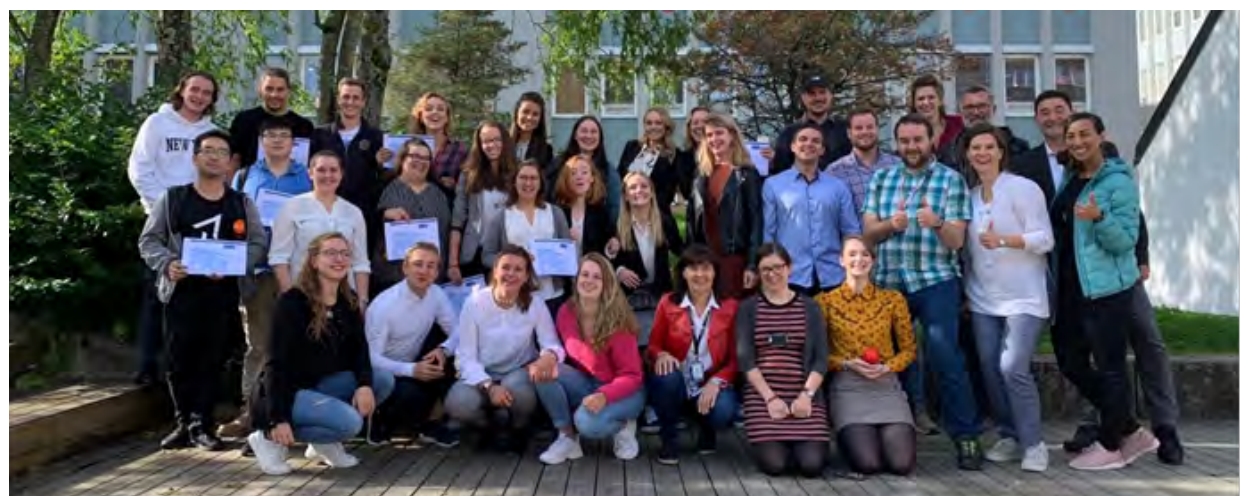

_ Figure 4. EuroFM Summer School participants, September 2019 (Author's own) 
NTNU is an anchor of academic, work and community life in Trondheim, Norway, and enjoys close collaboration with the municipality as an innovation lab for co-creation (Trondheim Kommune, 2019). The university and surrounding innovation ecosystem make Trondheim Norway's Innovation Capital. In alignment with the university's strategic research areas - energy, health, oceans and sustainability - and enabling technologies, the relationship between technology and society comes to the fore in its activities. Co-creation has interdisciplinary applications and is put to use in civil and environmental engineering, architecture and planning, geography, health, psychology, sociology, and so on, and therefore has a strategic use for achieving the university's motto, Science for a better world.

In the area of PEDs, NTNU hosts several projects funded by the EU Horizon 2020 programme and Research Council of Norway, including: FME ZEN-Research Centre on Zero Emission Neighbourhoods in Smart Cities, +CityxChange and Syn.ikia-Sustainable Plus Energy Neighbourhoods.5F CityxChange is unique amongst these in its citizen engagement approach.

Within +CityxChange, Trondheim Lighthouse City targets two demonstration sites: Brattøra, on the city's formerly industrial harbour, and Sluppen, an industrial area that is currently being transformed to mixed use. A third site, NTNU's main university campus, Gløshaugen, serves as a further testing ground and is a PED demo site within FME ZEN. These areas are highlighted in Figure 5. Innovation labs are planned or in operation in these three sites, plus at the Trondheim the city hall, Bytorget. The frameworks described above are to be implemented in the +CityxChange demo sites and can be tested in other NTNU projects.

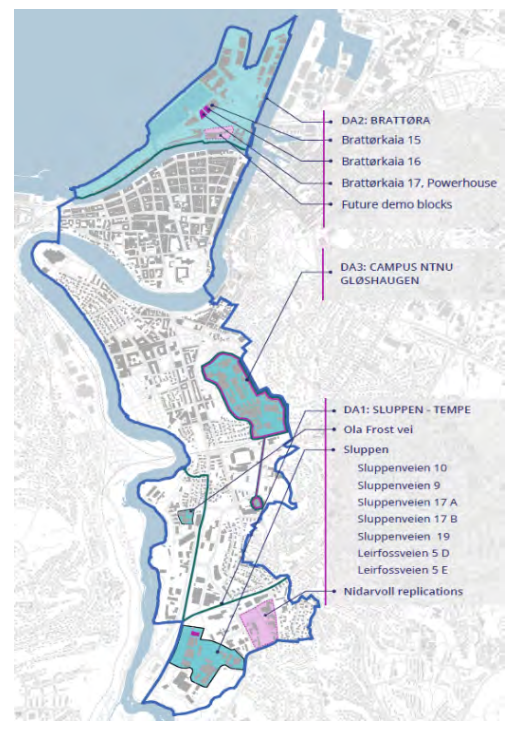

_ Figure 5: Trondheim Lighthouse City (+CityxChange, 2019b)

In the early stage of + CityxChange, which is finishing its second year, learning activities are underway to support the creation of the learning framework for the next generation of smart citizens. Professors and lecturers involved in the project presented the concept of co-creation to students of civil engineering, particularly in facility management, to stimulate and inspire diverse projects about sustainable refurbishment. For many of them, it is their first introduction to co-creation and the idea that citizens should be actively involved in shaping their environment. Engineering students are challenged to adopt a socially-oriented perspective alongside their use of technical solutions for building performance. Bachelor and master students in two summer schools held at NTNU in 2019 studied the sites being transformed in the +CityxChange project. They were given an introduction to 
the project before conducting field research and developing tools for co-creation in these and other sites throughout Trondheim.

The students underwent brainstorming as an educational tool. This was particularly effective for engaging technologically oriented students from engineering programmes in social and community-based approaches to investigate user-based solutions. Furthermore, in the field, they interviewed users (residents) in various neighbourhoods and met with community association and business representatives (Figure 6).
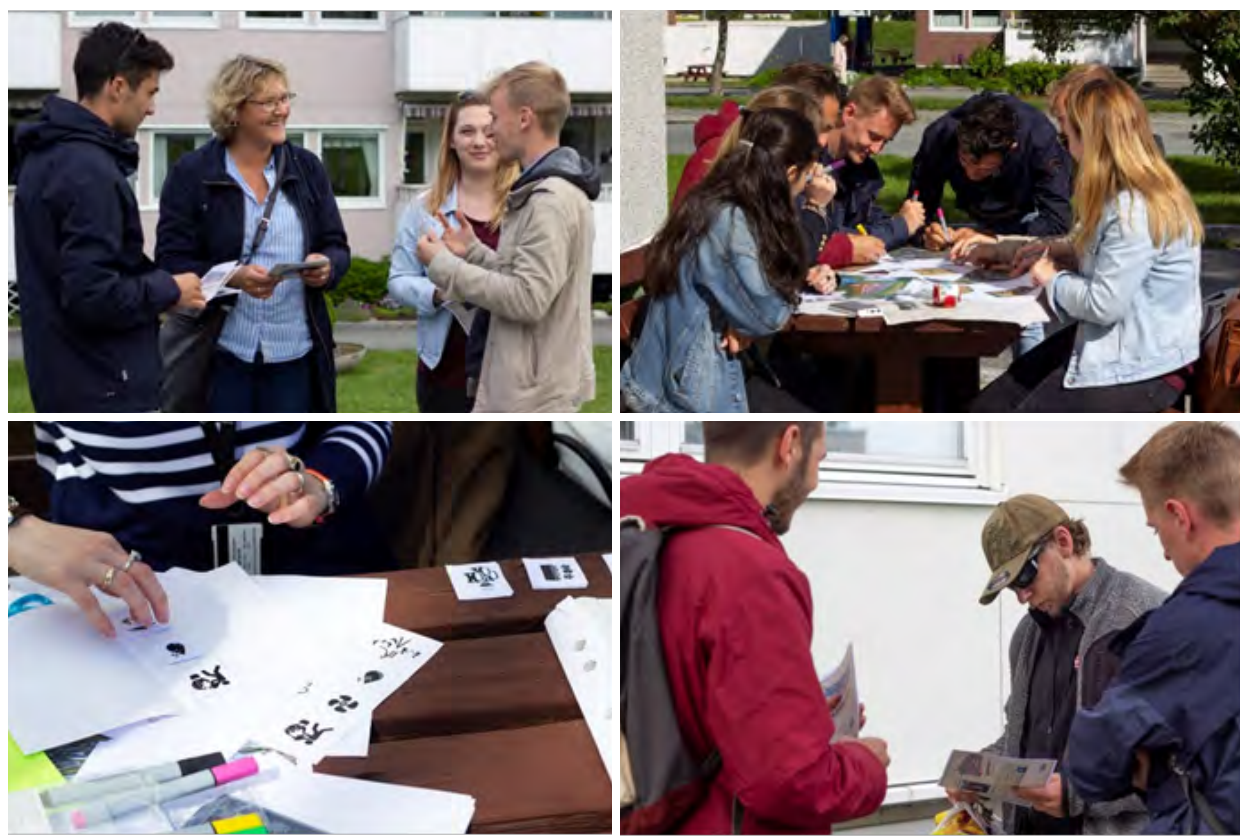

_ Figure 6: Civil engineering students in fieldwork (Author's own)

As a contribution to the learning framework for the next generation of smart citizens in particular, information from the summer schools was structured into a framework template. The activities are then filed in the +CityxChange Learning and Education Portfolio website as an example for potential users to replicate.

\section{CONCLUSION: CO-CREATION FOR SMARTER CITIES: SMART CITIZENS}

Citizen engagement through co-creation activities in +CityxChange is oriented towards multi-generational learning in cities, empowerment of citizens to become energy champions and activating innovation labs as places for stakeholder interaction with citizens. Experiences of NTNU within the project have contributed to the creation of frameworks for citizen participation, notably related to education. Activities undertaken at NTNU for civil engineering students are an example of such activities targeting future professionals who will potentially become champions for the energy transition. This segment of next generation smart citizens will be shaped by building new values of citizen engagement in a traditionally technocratic top-down profession. Other activities undertaken in the project will target elementary school-aged children and the elderly in order to drive the energy transition and progress in sophistication.

The next generation of smart citizens will seek engagement in professional and personal aspects of their environment. In the building sectors, more widespread engagement will contribute to educat- 
ing citizens on their energy use, affecting their personal behaviour and decision-making, and also increase their technical knowledge and understandings of complex systems such as PEDs, which is needed to convince citizens to make the necessary investments to upgrade their own buildings, for example, and recognize the long term benefits of making such investments today.

Co-creation is a necessary element for driving a cultural shift towards more sustainable lifestyles. Managing the transition and integrating across the public, private and people sectors is crucial for the successful widespread adoption of complex initiatives like PEDs. The learning framework developed and tested at NTNU already indicates some recommendations for future users (Avram, in draft). It highlights the need to create a learning strategy for cities to ensure consistency, design events and learning resources together with target groups (co-creation) to discover the needs of the groups, and to establish bi-directional communication channels for knowledge transfer and new competencies. As the citizen participation and learning frameworks are put into wider use within the innovation labs, all stakeholders will be poised to learn and improve upon the processes for interaction with citizens and governance of smart cities.

\section{ACKNOWLEDGEMENT}

We gratefully acknowledge that part of this work has been performed within the +CityxChange6F (Positive City ExChange) project under the Smart Cities and Communities topic that has received funding from the European Union's Horizon 2020 research and innovation programme under Grant Agreement No. 824260.

\section{REFERENCES}

_ +CityxChange. 2019a. "+CityxChange: Objectives." Accessed February 26, 2020. https://cityxchange. eu/objectives/.

- +CityxChange. 2019b. "+CityxChange." Accessed February 26, 2020. https://cityxchange.eu/.

- Ahlers, Dirk; Driscoll, Patrick; Wibe, Håvard; Wyckmans, Annemie. 2019. "Co-Creation of Positive Ener-

gy Blocks." IOP Conference Series: Earth and Environmental Science 352, 012060.

- Arnold, Marlen. 2017. "Fostering sustainability by linking co-creation and relationship management concepts." Journal of Cleaner Production, 140, 179-188.

_- Avram, Gabriela. In draft. D3.4: Framework for DPEB Learning and Education. +CityxChange.

_ BPIE - Buildings Performance Institute Europe. 2017. "97\% of Buildings in the EU Need to be Upgraded." Factsheet. Last modified October 26, 2017. Accessed March 2, 2020. http://bpie.eu/publication/97of-buildings-in-the-eu-need-to-be-upgraded/

- Burón, Javier; Sánchez, Magda. 2020. "D3.2: Delivery of citizen participation playbook." +CityxChange Deliverable D3.2. Accessed October 8, 2020. https://cityxchange.eu/wp-content/uploads/2020/02/ D3.2-Delivery-of-the-citizen-participation-playbook.pdf

_- Curley, Martin; Salmelin, Bror. 2018. Open Innovation 2.0: The New Mode of Digital Innovation for Prosperity and Sustainability. Cham: Springer.

_ EC - European Commission. 2016. “Commission Recommendation (EU) 2016/1318 of 29 July 2016 on guidelines for the promotion of nearly zero-energy buildings and best practices to ensure that, by 2020 , all new buildings are nearly zero-energy buildings (OJ L 208, 2.8.2016, p. 46)." EUR-Lex - 32016H1318 EN. Brussels: European Commission.

_ EC - European Commission. 2018a. "The Strategic Energy Technology Plan - at the heart of energy research and innovation in Europe." Luxembourg: Publications Office of the European Union.

- EC - European Commission. 2018b. "Directive (EU) 2018/2002 of the European Parliament and of the Council of 11 December 2018 amending Directive 2012/27/EU on energy efficiency (Text with EEA relevance)." EUR-Lex - 32018L2002 - EN. Brussels: European Commission. 
_ EC - European Commission. 2018c. "Directive (EU) 2018/844 of the European Parliament and of the Council of 30 May 2018 amending Directive 2010/31/EU on the energy performance of buildings and Directive 2012/27/EU on energy efficiency (Text with EEA relevance)." EUR-Lex - 32018L0844 - EN. Brussels: European Commission.

_ EC - European Commission. 2018d. "Communication from the Commission - A Clean Planet for All: A European strategic long-term vision for a prosperous, modern, competitive and climate neutral economy. COM(2018) 773 final." EUR-Lex 52018DC0773. Brussels: European Commission.

- EC - European Commission. 2019a. "Communication from the Commission - The European Green Deal. COM(2019) 640 final." EUR-Lex 52018DC0773. Brussels: European Commission.

_ EC - European Commission. 2019b. "Horizon 2020 Work Programme 2018-2020: Climate action, environment, resource efficiency and raw materials." European Commission Decision C(2019)4575. Brussels: European Commission.

- EC - European Commission. 2020. "Smart Cities and Communities - LC-SC3-SCC-1-2018-2019-2020." Horizon 2020 - Work Programme 2018-2020: 10. Secure, clean and efficient energy. Accessed October 13, 2020. https://ec.europa.eu/research/participants/data/ref/h2020/wp/2018-2020/main/ h2020-wp1820-energy_en.pdf

_ Fitzgerald, Helena; Mee, Alan. In draft. "D3.5: Framework for a Positive Energy Champion Network." + CityxChange.

_ Fitzgerald, Helena; Burón García, Javier; Sánchez Mora, Magdalena. In draft. "D3.6: Framework for DPEB Innovation Labs." +CityxChange.

_ Gohari, Savis; Ahlers, Dirk; Nielsen, Brita F.; Junker, Eivind. (2020). "The Governance Approach of Smart City Initiatives. Evidence from Trondheim, Bergen, and Bodø." Infrastructures, 5 (4), 31.

_ Haldorsen, Tor Kristian Overå. 2016. "Norwegian Implementation of EU Directives on Energy Efficiency: Assessing and Explaining Variation." Master thesis, Department of Political Science. Oslo: University of Oslo.

_ JPI Urban Europe. 2018. "SET Plan Action 3.2. Implementation Plan related to Positive Energy Districts (PED)." Accessed September 9, 2020. https://setis.ec.europa.eu/actions-towards-implementing-integrated-set-plan/implementation-plans

_ Lindkvist, Carmel; Temeljotov Salaj, Alenka; Collins, David; Bjørberg, Svein; Haugen, Tore Brandstveit. 2020. "Exploring urban facilities management approaches to increase connectivity in smart cities." Facilities, ahead-of-print.

_ Ministry of Climate and Environment. 2017. "Act relating to Norway's climate targets (Climate Change Act) [Lov om klimamål (klimaloven)]." LOV-2017-06-16-60. Accessed March 2, 2020. https://lovdata.no/ dokument/NLE/lov/2017-06-16-60

_ Ministry of Petroleum and Energy. 2012. "Consultation on the review of Directive 2012/27/EU on Energy Efficiency." Government of Norway. Accessed March 2, 2020. https://www.regjeringen.no/contentassets/ ca446f4845bf473ea3ae82d1bb63454d/consultation-on-the-review-of-energy-efficiency-directive.pdf

- Tanum, Øyvind; Mjøen, Kristian; Reeves, Kieran; Solhaug Næss, Kristin. 2019. “D3.1: Framework for Bold City Vision, Guidelines, and Incentive Schemes (SDG City Transition Framework)." +CityxChange Deliverable D3.1. Accessed October 8, 2020. https://cityxchange.eu/knowledge-base/framework-forbold-city-vision-guidelines-and-incentive-schemes/

- Temeljotov Salaj, Alenka; Gohari, Savis; Senior, Coline; Xue, Yan; Lindkvist, Carmel. 2020. "An interactive tool for citizens' involvement in the sustainable regeneration." Facilities, 38 (11/12), 859-870.

- Trondheim Kommune. 2019. "TRD3.0 - Universitetskommune." Accessed 14.10.2020. https://sites. google.com/trondheim.kommune.no/universitetskommunen/hjem

_ UNCED. 1992. "Agenda 21." United Nations Conference on Environment \& Development, Rio de Janeiro, Brazil, 3 to 14 June 1992. Accessed October 8, 2020. https://sustainabledevelopment.un.org/content/ documents/Agenda21.pdf

_ UN - United Nations. 2015. "Transforming our world: the 2030 Agenda for Sustainable Development." A/RES/70/1. New York: The United Nations. Accessed March 2, 2020. https://sustainabledevelopment. un.org/post2015/transformingourworld 